\title{
Implementation of Sector Policing in Hillbrow
}

\author{
Ramolobi Louis Gemane Matlala* \\ Deputy Director: Policy and Research, Gauteng Department of Community Safety, Street Address \\ 64 Prichard Street, Johannesburg, 2000, Postal Address: P.O. Box 4498, Brits, 0250 \\ E-mail Address: ramolobi.matlala@gauteng.gov.za / ramolobi.matlala@gmail.com
}

\section{Doi:10.5901/ajis.2015.v4n3p135}

\begin{abstract}
Sector policing is one of the "new" policing methods introduced by the South African Police Service (SAPS) in the post democratic South Africa1. The purpose of this exploratory study was to investigate the implementation of sector policing in Hillbrow, a suburb in the City of Johannesburg, South Africa. The study assessed the roles of different stakeholders in the application of the sector policing approach in the research area. The scientific inquiry employed the case study research design, while data was collected through semi-structured as well as focus group interviews. The study confirmed that application of sector policing have yielded positive outcomes in terms of preventing and combating crime in Hillbrow. This includes improve police service delivery as well enhanced community-police relations. It was also found that there is a variety of challenges that limit the effectiveness of sector policing in the area. These incorporate, among others, allegations of criminality by some of the members of the SAPS and Patrollers based in Hillbrow, inadequate training and insufficient resource allocation. In order to intensive the fight against crime in Hillbrow, it is recommended that more resources should be allocated and key stakeholders involved in the implementation of sector policing should be adequately trained
\end{abstract}

Keywords: sector policing, community policing, problem-oriented policing, crime prevention.

\section{Introduction}

Police agencies have since acknowledged that the "war" against crime cannot be won by relying solely on conventional policing approaches such as preventative patrols, rapid responses and follow-up criminal investigations (Kelling \& Moore 1998). The limitation of conventional policing approaches has resulted in the introduction of innovative policing methods, for instance, community policing and problem-oriented policing methods over the past three decades (Centre for Problem Oriented Policing no date).The emphasis on problem-solving as a key element of community policing stems from the pioneering work on problem-oriented policing done by Herman Goldstein in the late 1970's and experiments conducted in Newport News, England in 1984 (Centre for Problem Oriented Policing no date). Similarly, the South African Police Service (SAPS) has introduced a series of strategies to curb the escalating level of crime in South Africa. These includes the adoption of the community policing philosophy (Department of Safety and Security 1995; Department of Safety and Security 1997) as well as the National Crime Prevention Strategy of 1996 (Department of Safety and Security 1996). The SAPS has also espoused the sector policing approach (SAPS 2003) which has been discussed as far back as 1998, but its implementation has only been realised from 2006 (Dixon \& Rauch 2004). All police stations in South Africa are enjoined to implement sector policing, regardless of variations in their local policing needs and priorities. The purpose of this paper is to explore the implementation of the sector policing method in the Hillbrow. The study was motivated by the assumptions that crime is generally getting out of control in the area, and that given its design and other dynamics, sector policing might not enable the SAPS to prevent and combat crime successfully in the area. The rest of the paper comprises of literature review, research methodology as well as findings of the study.

\section{Literature Review}

This section presents a brief profile of Hillbrow, the origin of sector policing and sector policing in South Africa.

1 South Africa has been under minority rule until the democratic elections held in April 1994. 


\subsection{The Profile of Hillbrow}

Hillbrow is regarded as one of the most densely populated neighbourhoods in the City of Johannesburg. It is estimated that there are approximately 1 million residents accommodated in about 200 high-rise apartment blocks within an area of $1.5 \mathrm{~km}^{2}$ (City of Johannesburg 2009). Furthermore, residential occupation in this area has increased by more than two fold within 20 years (i.e. between 1989 and 2009). This increase in residential occupation was nonetheless not accompanied by a corresponding increase in the development of additional residential accommodation (City of Johannesburg 2009). The disjuncture between occupancy rates and the development of new flats has resulted in overcrowding. As a result, Hillbrow has been characterised by the development of slums due to sub-letting of units which could be attributed to the scarcity of affordable accommodation accompanied by a fixed supply of residential units in the area (City of Johannesburg 2009). In addition to the overcrowding, there is also a perception that Hillbrow is a dangerous place which is characterised by social problems and crime, particularly the drug trade and prostitution (Leggett 2002). It could therefore be assumed that criminal activities perceived to be taking place in the congested high rise buildings might not necessarily be combated through visible policing as a means of implementing sector policing (SAPS no date). It is further assumed that the congested and dilapidated high-rise buildings in Hillbrow area might present a challenge in the implementation of sector policing.

\subsection{The origin of sector policing}

The concept of sector policing could be traced from the United States of America and Britain during the 1970s and the 1990s respectively. It was part and parcel of policing innovations that were introduced and implemented to prevent and combat increasing levels of crime in these countries. This method of policing adopts a decentralised approach to policing, as opposed to traditional policing. Sector policing is therefore intended to be a service enhancement strategy. It is meant to address the causes of crime at a specific geographic location. This approach to policing requires tailor-made policing responses that are in tandem with local policing needs and priorities. Furthermore, sector policing seeks to achieve community participation in crime prevention initiatives (Dixon \& Rauch 2004; Buthelezi 2012).

\subsection{Sector policing in South Africa}

This section focuses on the definition of sector policing, policy framework underpinning sector policing in South Africa, principles underpinning implementation of sector policing and linkages between community policy and sector policing.

\subsubsection{Definition of sector policing}

Steinberg (2005: 27) contends that "Sector policing is a vague and amorphous term which has been through a thousand definitions and redefinitions". That said, the White Paper on Safety and Security (Department of Safety and Security 1998) defines sector policing as a method of policing smaller and manageable geographic areas within a police station. The South African Police Service (SAPS) embraces this definition but also views sector policing as a sub-component of Visible Policing which incorporates preventive patrol; directed patrol and high density policing (SAPS 2003). Furthermore, the SAPS regards sector policing as an operational mechanism intended to ensure successful implementation of community policing (SAPS 2003). The SAPS (2003) cited in Maroga (2004) also maintains that sector policing is geared towards identifying the root causes of crime in a particular sector. Additionally, this method of policing is viewed as a means of improving relations between the police and communities (SAPS 2003; Maroga 2004). Sector policing is therefore geared towards ensuring that the police are in fact accountable to the communities they serve (SAPS 2003; Maroga 2004). Montesh (2007), on the other hand, concurs with the notion of sector policing as a tool for promoting police accountability in sectors. He also views the policing method multi-layered policing approach aimed at maximising visible policing through sector teams as well as means of improving community-police relations in sectors (Montesh 2007). The definitions outlined above portray sector policing as one of the most dynamic policing methods in a sense that it employs a variety of policing approaches in order to prevent and combat crime in sectors. Furthermore, this policing approach is thought to be a means of enhancing effective policing by demarcating a police station into small and manageable policing areas. 


\subsubsection{Policy framework underpinning sector policing in South Africa}

This sub-section focuses on the White Paper on Safety and Security of 1998 as well as the National Instructions on Sector Policing that were circulated by the national office of the SAPS between 2003 and 2013.

\subsubsection{The White Paper on Safety and Security}

The notion of sector policing was first introduced in the White Paper on Safety and Security (Department of Safety and Security 1998). According to the White Paper, this method of policing should be conducted in a proactive, vigorous and fair manner (Department of Safety and Security 1998). It should also be based on clear instructions from the sector commanders who are in charge of respective sector teams (Department of Safety and Security 1998). Furthermore, sector policing should be planned on the basis of crime analysis (Department of Safety and Security 1998:22). The development of partnerships with the municipal police and other relevant stakeholders is also advocated, although there is no indication of what the roles of these stakeholders should be (Department of Safety and Security 1998).

\subsubsection{National Instructions on Sector Policing}

The circulation of the first National Instruction on Sector Policing, the Final Draft National Instruction of 2003 paved the way for the implementation of sector policing in South Africa. This document prescribes the four steps that must be followed to implement sector policing at police station level. These steps are dividing the police station into manageable sectors, appointment of Sector Commanders and Sector Team members, compilation of sector profiles and establishment of the Sector Crime Forums (SAPS 2003 in Maroga 2004). The rationale behind the phased approach was intended to empower the management of SAPS in police stations to monitor progress, locate any challenges that may arise during the early stages of implementation and to put in place remedial measures to address identified implementation challenges (SAPS 2003 in Maroga 2004). The Final Draft National Instruction of 2003 was followed up by the Divisional Instruction on Sector Policing of 2006.

The Divisional Instruction was a further attempt by the leadership of the SAPS to institutionalise and integrate the concept of sector policing into the day-to-day operations of the service (SAPS 2006). There is a notable similarity between the Draft National Instruction on Sector Policing of 2003 and the Divisional Instruction of 2006 in terms of the implementation of sector policing, namely, determining boundaries to establish sectors, appointment of Sector Commanders and Sector Teams, compilation of the sector profile and establishment of the Sector Crime Forums. There are also explicit differences in terms of details and emphasis between the two documents. Unlike the first National Instruction which was basically about introducing sector policing and outlining the process of executing the strategy, the Divisional Instruction goes a step further to define key concepts that are closely related to the implementation of sector policing approach. These include the definition of "sector", "sector policing", "sector commander" and the "sector team". Furthermore, this document is categorical about the roles and responsibilities of key personnel in SAPS at national, provincial, cluster and even police station level in relation to the application of sector policing (SAPS 2006). The Divisional Instruction of 2006 was supplemented by the Sector Policing National Instruction 3 of 2009.

The purpose of the 2009 National Instruction was "to regulate the implementation of sector policing in the service" (SAPS 2009). This document is nonetheless silent on what the regulation of the implementation of sector policing means or how it will be achieved. The 2009 National Instruction purports to revoke the Final Draft National Instruction of 2003 and the Divisional Instruction issued in 2006. It is however not clear how the third National Instruction revokes the previous documents because it still advocates the phased approach in the implementation of sector policing (SAPS 2009). Furthermore, definitions such as "sector", "sector policing" and "sector commander" referred to in the earlier National Instructions are still used in the 2009 National Instruction (SAPS 2003; SAPS 2006; SAPS 2009). It is nonetheless worth mentioning that there are new internal role players with specific responsibilities introduced through this document, namely, "sector co-ordinators" which are responsible for administrative functions of sector policing at the level of the police stations, "relief commanders" responsible to select and post sector teams in sectors in collaboration with the sector commanders, as well as "operational commanders" who designated by the relief commanders to take command and control of the sector teams for the duration of the shift) (SAPS 2009). In terms of the implementation of sector policing, the National Instruction of 2009 remains ambiguous about a number of issues, particularly on determining the boundaries of sectors and the compilation of sector profiles. This document makes mention of "thoroughly analysing the station profile" and "consultation with operational role-players and relevant community representatives..." without 
providing specifics (SAPS 2009). There is also mention of the "regular review" of sector profiles without prescribing timeframes for such reviews (SAPS 2009:4). This ambiguity might create uncertainty on the part of implementers, or may even hamper implementation as envisaged by the National Instruction. The fourth National Instruction was circulated in 2013.

The National Instruction number 3 of 2013 was circulated "to provide minimum standards to regulate the implementation of sector policing" (SAPS 2013:1). The document lists 12 objectives of sector policing. These include, among others, crime prevention, improving visible policing, as well as to establish the formation of partnerships between the police and communities (SAPS 2013: 2). The National instruction is, however, not explicit on how these objectives will be achieved. Furthermore, some of the objectives cited in the National Instruction are less likely to be achieved through sector policing. The case in point is improvement of crime investigation and the establishment of informer network which are purely a function of the Detective Service with separate command and control structure different from that of the Sector Teams. The 2013 National Instruction also sets four "minimum standards" as prerequisites for the implementation of sector policing. These are demarcation of policing area into manageable sectors, appointment of sector commanders, deployment of human and material resources to implement sector policing, as well as the establishment of Sector (Crime) Forum (SAPS 2013). These so-called "minimum standards" are in actual fact a repetition of the four-phase approach advocated by the 2003 National Instruction; hence it is not clear what value is this aspect of the National Instruction adding to the implementation of sector policing in police stations.

\subsubsection{Principles underpinning implementation of sector policing}

The implementation of sector policing is grounded on principles that were adopted from the community policing philosophy. The London Metropolitan Police Guidelines on sector policing advocates principles that should be upheld while implementing sector policing (Dixon \& Rauch 2004). These are effective utilisation of resources allocated to the police; improving working relations between the police and local communities; the ownership, identification and addressing underlying causes of crime in localities and encouraging visible policing by local offices known to the communities (Dixon \& Rauch 2004). The rationale behind these initiatives is to improve policing (Dixon \& Rauch, 2004). The South African version of sector policing has distinctive features, namely, Problem solving, and Community consultation

Problem solving or what has come to be known as 'problem-oriented policing' as introduced by Goldstein (1990). This scholar argues in favour of the notion that "the main units of police business consists of a wider range of substantive community problems that manifests themselves in clusters of similar, related, or recurring incidents". Goldstein is therefore not a proponent of strict law enforcement as the pen ultimate goal of policing. For him, the role of the police is to identify and analyse substantive community problems with a view of developing and evaluating specific solutions in an area (Goldstein 1990 cited in Dixon \& Rauch 2004:16). People oriented policing is characterised by a four stage approach popularly referred to as 'SARA' (Scanning, Analysis, Response and Assessment). "Scanning" has traditionally been done by the police relying on their own knowledge and experience of the areas they are serving without the input of affected communities. This tendency resulted in the police resorting to the 'crime-fighter' mode of targeting groups which are traditionally out of favour with them (Eck \& Spelman 1987 cited in Dixon \& Rauch, 2004; Centre for Problem-oriented Policing no date). This might further aggravate tension between the police and some members of communities, thus rendering people-oriented policing ineffective in tackling crime.

"Analysis" involves learning everything possible about the players, incidents and actions already used to try to deal with the problem. This aspect of the SARA model should be as thorough, creative and innovative because the characteristics of each problem vary. Comprehensive analysis of a problem is therefore critical to the success of a problem-solving effort. Effective tailor made responses cannot be developed unless one knows what is causing the problem (Eck \& Spelman 1987 cited in Dixon \& Rauch 2004; Centre for Problem-oriented Policing no date) The third element of the SARA, "Response", is based on the scanning and analysis phases. Different tailor-made responses can be designed. These include eliminating the problem, reducing the problem, reducing the harm created by the problem, addressing the problem more effectively or even remove the problem from the consideration of the police (Eck \& Spelman 1987 cited in Dixon \& Rauch 2004; Centre for Problem-oriented Policing no date). The final process of the SARA, "Assessment", involves evaluating the effectiveness of a response or a combination of responses. These may include total elimination of the problem, more effective handling of the incidents or an improved response to the problem, reduction in the volume of calls for service or reported crime, satisfied residents or businesses and when policy makers notice a difference in complaints (Eck \& Spelman 1987 cited in Dixon \& Rauch 2004; Centre for Problem-oriented 
Policing no date). On the other hand, community consultation in policing could be traced back to 1984 in the UK (Dixon \&Rauch 2004). Informal and voluntary arrangements between the police and communities were replaced by formal consultative processes enshrined in statute (Dixon \& Rauch 2004). The same could be said about South Africa where Community Policing Forums are a creation of legislation (i.e. section 18 of the South African Police Act 68 of 1995 as amended). Historically, Community Policing Forums are not well known for their effectiveness. It remains nonetheless to be seen if community policing in the context of Sector Crime Forums will yield desirable outcomes, namely, contribute towards preventing and combating crime in sectors (Dixon \&Rauch 2004).

\subsubsection{Linkages between community policing and sector policing}

The SAPS argues that sector policing does not contradict the philosophy of community policing, but should rather be viewed and implemented within the framework of community policing (SAPS 2003 cited in Maroga 2004). It is therefore imperative to ensure that Sector Crime Forums are grounded within the same core elements that underpin Community Policing Forums. These elements are service orientation and accountability by the police, establishment of partnerships between the police and communities, providing solutions to factors responsible for escalating crime in sectors and empowering communities to be effective partners in the fight against crime (SAPS 2003 cited in Maroga 2004). In summing up, it could be argued that sector policing is not intended to replace community policing. Instead, later should be viewed as a grass-root policing approach that reinforces community policing. This however requires the police to effectively take policing services to communities.

\section{Research Methodology}

The study utilised the case study research design and the qualitative research approach. Data was collected through semi-structured interviews with members of the SAPS, chairpersons of the Community Policing Forum and the Sector Crime Forum based at the Hillbrow Police Station, officials of the Department of Community Safety in the Gauteng Province as well as experts in the field of policing. The study also collected data through focus group interviews with Community Patrollers and members of the Sector Crime Forum in the area.

\section{Findings}

This section constitutes the findings as the discussion of the findings of the study. It discusses the roles of key stakeholders in the implementation of sector policing, allocation of resources to the sector team, the relationship between the Sector Crime Forum, the Sector Team and the Community Policing Forum, and benefits as well as the challenges of implementing sector policing in Hillbrow

\subsection{Roles of key stakeholders in the implementation of sector policing}

The sector policing approach was put into operation in Hillbrow in 2006 as per the instruction of the Provincial Commissioner. The key role players in the implementation of sector policing are the Station Commander, the Sector commander, the Sector Team as well as the Sector Crime Forum (SCF). The primary role of the Station Commander is to appoint Sector commanders. A decision was taken by the leadership of SAPS to appoint officers on the level of Captain to manage the sectors. The reason cited for this decision was that Captains are more senior and therefore have the required authority to lead the sector teams better than junior colleagues. The appointment of Captains as sector commanders was confirmed and supported members of the Community Policing Forum who further argued that the decision has resulted in improved leadership and management of the sector. The argument on the appointment of Captains as sector commanders was nonetheless disputed by one of the policing experts who argued that the rank of a sector commander does not matter, what is key is to appoint police officials with the right personality and attitude, purpose, initiative and who are resourceful. This implies that not every police official, regardless of their rank, may be an effective sector commander. It also suggests that the Station Commander should only appoint police officials with the requisite attributes to manage the sectors. This might be true to some extent, but given that the SAPS by its very own nature is a rank conscious institution, a lower ranking officer might not enjoy the authority and respect among members of the sector teams as opposed to the more senior members. The role of the Sector Commander is threefold. Firstly, the Sector Commander is responsible for ensuring that the SCF is established and functional. Secondly, they are responsible 
for compiling and updating the Sector Profiles quarterly. Thirdly, the Sector Commander is also responsible for monitoring the radio communication and complaints from the community with an intention to ensure that they are responded to in time. On the other hand, the Sector Team for Hillbrow comprises 18 members, namely, the Sector Commander, the Deputy Sector Commander, one SAPS Constable, three SAPS Reservists as well as 12 Street Patrollers. The deployment of the sector team in the area is based on crime patterns. This implies that positioning of the team is based on crime analysis of the crime hotspots. It was found that absenteeism by any member of the SAPS has a negative effect on the ability of the Sector Team to discharge their duties effectively given that there is no relief team. The study also confirmed that the Street Patrollers are indeed part of the Sector Team. The role of the Patrollers is to help police to fight crime by arresting suspects in possession of illegal firearms, knives, drugs and stolen cellular phones from time to time under the supervision of SAPS officials. The study found that the implementation of sector policing in Hillbrow is hamstrung skills about this policing approach. Buthelezi (2012) argues the lack of skills could be attributed to limited training, if any, received by the members of the SAPS about sector policing.

The SCF comprises of ten members, namely, the chairperson and his deputy, the secretary and the deputy secretary, as well as six additional members. The role of the chairperson of the Forum is to ensure that there are good relations between the police and various stakeholders in the area. He is also responsible for putting in place programmes to address safety and security needs of residents through visible policing, street patrols and the participation of Johannesburg Metropolitan Police Department and to ensure deployment of personnel and vehicles to crime hotspots in Hillbrow. The chairperson is also responsible for initiating projects to enlighten the community about tactics used by criminals and other crime prevention programmes of the Gauteng Provincial Government. The SCF communicates with the police because the Sector commander is always "on the ground". The Forum also provides information to the police about anybody suspected of criminal behavior, including the perpetration of domestic violence. Members of the Forum understand their role to be that of helping the police to fight crime in the sector. They argued that the police cannot be everywhere at the same time, thus the community should interact with the police and provide them with information about criminals and illegal activities taking place in the sector. This provides a clear understanding of the role of the SCF and therefore training requirements for members of the forum. Despite the active role played by the SCF in the fight against crime, members of this crime prevention structures lacks knowledge about the sector policing approach, this limits their ability to hold the police accountable.

\subsection{Allocation of resources to the Sector Team}

Sector policing is a resource intensive policing approach. It requires resources other than personnel of its successful implementation. Buthelezi (2012) argues that lack of adequate resources such vehicles and telecommunication devices (cellular phones) are an impediment towards effective implementation of sector policing. In Hillbrow, three vehicles have been allocated for patrolling and responding to complaints in the sector. Although the allocation is above the stipulated norm of two vehicles per sector, three vehicles are inadequate to effectively service the sector. Each of the sector vehicles is dispatched with two police officers and they are allocated one cellular phone which must be functional at all times. Reluctance to allocate additional resources for sector policing might imply that there is no complete buy-in on the part of the leadership of the SAPS to fully implement sector policing (Buthelizi 2010). The apparent reluctance might be attributed to the inability of the SAPS to fully embrace the philosophy of problem-oriented policing (Montesh 2007).

\subsection{The relationship between the Sector Crime Forum, the Sector Team and the Community Policing Forum}

The Hillbrow Community Policing Forum (CPF) is empowered by legislation (the SAPS Act of 1995) to oversee the Police Station, but there is no legislative clarity regarding the role of the SCF. Despite the legislative gap on the role of the Sector Crime Forum (SCF), the Sector commander and the Sector Team are accountable to the SCF. The Forum exercises an oversight role over the Sector Team through monthly meetings and constant communication between the Sector Commander and the chairperson of the Forum. The business of the monthly meetings include discussions on crime trends in the sector, identification of hotspots, and suggestions on how the policing needs of the sector should be addressed.

There is also lack of legislative clarity in terms of the relationship between the CPF and the SCF and yet respondents were of the view that the SCF does not replace the CPF. There is also a view that community policing and sector policing are actually complementary. The fact of the matter is that the SCF is accountable to the CPF because the chairperson and the secretary of the forum are expected to attend monthly meetings, where they account about crime 
prevention initiatives in the sector. There is therefore a 'big-brother' attitude between the CPF and the SCF and not necessarily equal partnership between these community safety structures. This might be blamed on a lack of legislative status for the SCF. Members of the SCF are not receiving support from the CPF.

\subsection{The benefits of sector of implementing sector policing in Hillbrow}

The implementation of sector policing in Hillbrow has brought about some benefits. Sector policing was regarded by respondents as a "good" policing approach because "it works wonders, and therefore the way to go for modern day policing". This policing approach was hailed because of its ability to enhance manageability of the police station by reducing it into smaller and compact geographic areas (Servamus 2004; Montesh 2007). The Sector Team and the Sector Commander are in constant contact with the SCF and provide progress reports. It could be argued that the Sector Team is accountable to residents through the SCF. Furthermore, residents in Hillbrow are more willing to approach the police to report crime or to give them tip-offs about perpetrators of crime. This signals an improvement in relations between the community and the police which makes it possible for the police to form partnerships with different stakeholders in the sector to prevent and combat crime (Servamus 2004; Montesh 2007). Respondents also indicated that sector policing makes it possible for policing to be tailor-made according to the policing needs of the sector. For them, this method of policing comes with more visible policing, an increased feeling of security among residents, and a reduction in crime. This seems to be the case in Hillbrow because street patrollers have been roped-in to beef up the sector team. This is an innovation in the roll out of sector policing in line with some of the challenges pertaining to the sector. The implementation of sector policing has resulted in improved visible policing which increase the feeling of safety among residents, albeit temporary and deters perpetration of crime (Servamus 2004; Montesh 2007). The policing approach could be credited for eliminating the so called "no-go-areas" in Hillbrow which were notorious for rampant criminal activity. Sector policing is also hailed for improvement in the police response time in the sector. This implies that the application of this policing method enables the SAPS to identify and address crime hotspots in the sector (Servamus 2004; Montesh 2007), albeit not entirely.

\subsection{Challenges associated with the implementation of sector policing in Hillbrow}

Despite the benefits derived from implementing sector policing in Hillbrow, the success of this policing methods in limited by a number of challenges, paramount among these is the high rate of specific crimes such as dealing in illicit drugs as well as prostitution. These types of crime are dependent on crime intelligence and are not necessarily winnable though the sector policing. Other crime categories that are still prevalent in Hillbrow are Residential Robbery, Street Robbery, Residential Burglary, Assault and carjacking. The implementation of sector policing is also hamstrung by a number of crime generators in Hillbrow. These include the high influx of homeless people and undocumented foreign nationals who are often arrested for petty crimes and serious crimes respectively. The gains of applying sector policing in Hillbrow are reserved by criminal behaviour by some members of the SAPS and Patrollers. There is also challenge of limited community mobilisation, awareness and participation to advance the intentions of sector policing. This challenge is confirmed by Mahuntse (2007) and Maroga (2004). Some of the CCTV cameras installed in the sector are dysfunctional and do not cover all the areas in the sector, including some of the crime hotspots. Finally, the area design and related matters makes it difficult to implement sector policing effectively. These incorporate of overpopulation of in the sector which results in a high police to community ratio. There is also the issue of many high-rise buildings, most of which are in a state of disrepair with dysfunctional lifts. These buildings are not easy to access by the police and the Street Patrollers and yet it is alleged that crime is taking place in such buildings. Another impediment is the high number of hijacked buildings in Hillbrow.

\section{Conclusion}

This article draws four conclusions. Firstly, the South African Police Service (SAPS) has been implementing the sector policing method in Hillbrow since 2006. Secondly, the application of this policing approach had benefits for the area. These include improvements in service delivery, enhanced community-police relations as well as increase in the feeling of safety residents in the area. Finally, the effective implementation of sector policing in the is thwarted by challenges such as the number of high-rise building some of which are over-crowded and not easily accessible to the Sector Team, criminal activity by some SAPS members as well Patrollers in Hillbrow. In other to strengthen the implementation of 
sector policing in Hillbrow, a number of measures should be put in place. Firstly, the sector team should intensify the policing of crime hotspots in order to make significant inroads on crimes such as street robberies. Secondly, the leadership of the Detectives Unit of the SAPS should implement both conventional and unconventional methods of investigation to complement visible policing in Hillbrow. Furthermore, efforts to recruit and register informers should be intensified. Special attention should thus be paid on recruiting informers to infiltrate crime hotspots, buildings that are 'notorious' as havens of criminal activity and to penetrate organised crime syndicates purported to be operating in the area. Thirdly, the leadership of the SAPS should put in place measures to prevent corruption within its ranks and hold criminal elements in the organisation accountable to deter potential perpetrators. The leadership of the SAPS should also implement previously made recommendations with regard to improving police conduct and professionalism in Hillbrow. Fourthly, training for Sector Commanders and the members of the team to implement sector policing effectively should be bolstered. In addition, the leadership of the SAPS should improve resource allocation to enhance the application of sector policing. Finally, community awareness and participation about the sector policing method should be improved.

\section{Acknowledgement}

- The Gauteng Department of Community Safety (GDCS), South Africa funding of the research project

- Ms Tebogo Umanah, Director: Policy \& Research (GDCS) and Ms Duxita Mistry, Chief Director: Civilian Oversight (GDCS) for their valuable inputs

- Participants in the study

\section{References}

Buthelezi, M.W. 2012. Implementation of sector policing in the Province of Kwazulu-Natal: The case of Nongoma and Newcastle Police Stations. Unpublished dissertation submitted for the degree of Master of Technology in Public Management at the University of South Africa. Pretoria: Unisa.

City of Johannesburg, (2009), Urban Implementation Plan of the City of Johannesburg, [Online] Available: http://www.joburg-archive. co.za/2011/inner_city/udip2009_part3_pg54-63.pdf. Accessed 17 July 2013

Gauteng Department of Community Safety. (2014). Implementation of Sector Policing in Hillbrow. Johannesbug: GDCS

Department of Safety and Security. (1996). National Crime Prevention Strategy. Pretoria: Government Printers.

Department of Safety and Security. (1997). Community policing framework and guidelines. Pretoria: Government Printers.

Department of Safety and Security. (1998). White Paper on Safety and Security. Pretoria: Government Printers.

Department of Safety and Security. ( 2005). South African Police Act 68 of 1995. Pretoria: Government Printers.

Dixon, B. \& Rauch, J. (2004). Sector Policing: Origins and Prospects: Monograph no. 97, March 2004. Pretoria: Institute of Security Studies (ISS).

Kelling, G.L. \& Moore, M.H., (1998), The Evolving Strategy of Policing, National Institute of Justice. U.S. Department of Justice, and the Program in Criminal Justice Policy and Management John F. Kennedy School of Government: Harvard University. [Online] Available: http://www.ncjtc.org/CJCI/TRGP/Documents/Limitations\%20of\%20Conventional\%20Policing\%20Methods.pdf, Accessed 28 March 2014.

Leggett, T. (2002). A Den of Inequity? Inside Hillbrow's Residential Hotels. SA Crime Quarterly, 2: ISS

Mahuntse, SNN. (2007). Sector Policing in the Johannesburg Central Station Policing Area. Tshwane University of Technology, M. Tech: Policing.

Maroga, M. (2004). Sector Policing: What are the challenges? Johannesburg: Centre for the Study of Violence and Reconciliation.

Montesh, M. (2007). Poor infrastructure as an inhibiting factor in the implementation of sector policing at Calcutta police station in the Bushbuckridge Local Municipality. Acta Criminologica, 20 (3), 32-45.

South African Police Service (SAPS). (2003). Final Draft National Instruction on Sector Policing. Pretoria: SAPS.

SAPS (no dated), Sector Policing, [Online] Available: http://www.saps.gov.za/comm_pol/sector_policing/sector_policing.htm, Accessed 12 July 2013

SAPS. (2006). Divisional Instruction on Sector Policing. Pretoria: SAPS

SAPS. (2009). Instruction on Sector Policing. Pretoria: SAPS.

SAPS. (2013). National Instruction on Sector Policing. Pretoria: SAPS

Steinberg, J. (2004). Sector Policing on the West Rand: Three Case Studies. Monograph 110: Pretoria: ISS.

Steinberg, J. 2005. Sector policing that works: a case study of the West Rand SA Crime Quarterly no 11 March, 2005. Pretoria: ISS 